\title{
IROA: the International Register of Open Abdomen.
}

\section{An international effort to better understand the open abdomen: call for participants}

\author{
Federico Coccolini ${ }^{1 *}$, Fausto Catena ${ }^{2}$, Giulia Montori ${ }^{1}$, Marco Ceresoli ${ }^{1}$, Roberto Manfredi ${ }^{1}$, Gabriela Elisa Nita ${ }^{1}$, \\ Ernest E. Moore ${ }^{3}$, Walter Biffl ${ }^{3}$, Rao Ivatury ${ }^{4}$, James Whelan ${ }^{4}$, Gustavo Fraga ${ }^{8}$, Ari Leppaniemi ${ }^{6}$, Massimo Sartelli ${ }^{5}$, \\ Salomone Di Saverio ${ }^{7}$ and Luca Ansaloni ${ }^{1}$
}

\begin{abstract}
Actually the most common indications for Open Abdomen $(\mathrm{OA})$ are trauma, abdominal sepsis, severe acute pancreatitis and more in general all those situations in which an intra-abdominal hypertension condition is present, in order to prevent the development of an abdominal compartment syndrome. The mortality and morbidity rate in patients undergone to OA procedures is still high. At present many studies have been published about the OA management and the progresses in survival rate of critically ill trauma and septic surgical patients. However several issues are still unclear and need more extensive studies. The definitions of indications, applications and methods to close the OA are still matter of debate. To overcome this lack of high level of evidence data about the OA indications, management, definitive closure and follow-up, the World Society of Emergency Surgery (WSES) promoted the International Register of Open Abdomen (IROA). The register will be held on a web platform (Clinical Registers ${ }^{\circledR}$ ) through a dedicated web site: www.clinicalregisters.org. This will allow to all surgeons and physicians to participate from all around the world only by having a computer and a web connection. The IROA protocol has been approved by the coordinating center Ethical Committee (Papa Giovanni XXIII hospital, Bergamo, Italy). IROA has also been registered to ClinicalTrials.gov (ClinicalTrials.gov Identifier: NCT02382770).
\end{abstract}

Keywords: Register, Open abdomen, Peritonitis, Pancreatitis, Trauma, Management, Surgery

\section{Introduction}

The Open Abdomen (OA) was firstly described almost 120 years ago by Andrew J. McCosh [1]. No popularity was gained by this technique in treating several severe conditions before it has been applied extensively to the severely injured patients in a damage control surgical strategy. Actually the most common indications for OA are trauma, abdominal sepsis, severe acute pancreatitis and more in general all those situations in which an intra-abdominal hypertension condition is present, in order to prevent the development of an abdominal compartment syndrome (ACS) [2,3]. The mortality rates in

\footnotetext{
*Correspondence: federico.coccolini@gmail.com

'General Emergency and Trauma Surgery, Papa Giovanni XXIII Hospital, Piazza OMS 1, 24127 Bergamo, Italy

Full list of author information is available at the end of the article
}

patients underwent to OA are high, usually over $30 \%$ depending on the patient cohort and on OA causative event [4]. The OA management is a complex and challenging situation that requires a multidisciplinary approach. In fact only by a close cooperation between surgeons and the ICU team would be possible to obtain good results in terms of survival improvement and morbidity reduction. In case of ACS in fact a therapy aiming to achieve early opening and early closure is the key. The "old" paradigm to "close at any cost" the abdomen shifted toward a combination of medical and surgical therapies including negative pressure wound therapy and dynamic closure, that would lead to a reduction in mortality, morbidity and incisional hernia rate.

At present many studies have been published about the OA management and the progresses in survival rate of 


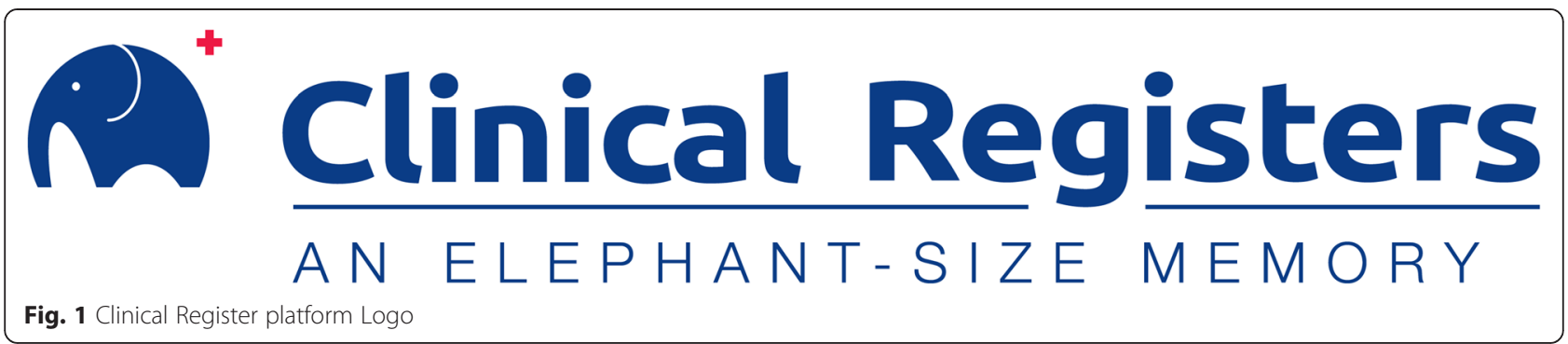

critically ill trauma and septic surgical patients. All these results have only been obtained thanks to the great work of pioneers, scientific societies and their guidelines [5-9].

At present however several issues are still unclear and need more extensive studies. The definitions of indications, applications and methods to close the OA are still matter of debate. No definitive data demonstrated the real differences between the different techniques to maintain the $\mathrm{OA}$ in terms of morbidity and mortality. Patients treated with OA procedures are absolutely heterogeneous even within the same study. Large cohorts of patients treated with the same procedures are rare. Moreover no definitive data exist about nutrition strategies. Neither the impact of the different kind of nutrition on the outcomes has been defined [10-13]. All existing studies accrued patients in at least a few centers with many different biases [14-18]. Even few systematic review and meta-analysis have been published about the topic but no definitive data could be obtained $[19,20]$. Lastly no sufficient data about the closure and follow-up of patients treated with OA strategies exist [21-23].

To overcome this lack of high level of evidence data about the OA indications, management, definitive closure and follow-up, the World Society of Emergency Surgery (WSES) promoted the International Register of Open Abdomen (IROA).

This prospective observational trial aims to enroll patients undergone to any kind of OA procedure.

The web-based philosophy of the register will give the opportunity to all surgeons and physicians members of ICU teams treating with OA patients to participate. The register will be held on a web platform (Clinical Registers ${ }^{\circ}$ ) through a dedicated web site: www.clinicalregisters.org (Fig. 1). This will allow to all surgeons and physicians to participate from all around the world only by having a computer and a web connection.

The data insertion will be possible after registration to the web platform. Each surgeon will get personal credentials that will allow him/her to register patients. Data will be enrolled and kept protected by a certified system of data encryptation.

The IROA protocol has been approved by the coordinating center Ethical Committee (Papa Giovanni XXIII hospital, Bergamo, Italy). IROA has also been registered to ClinicalTrials.gov (ClinicalTrials.gov Identifier: NCT02382770). All necessary documents can be downloaded from the register web-site. A free access web-site part will allow to all those who may need more information, to obtain them without the necessity of registration. Each year will be published a paper containing the registered data with all the names of participating physicians. All physicians who enrolled patients can ask to have their own data according to the protocol rules.

WSES strongly believe in the necessity to diffuse emergency and trauma surgery as well as acute care surgery knowledge and to create diffuse collaboration in worldwide scientific projects. For this reason the present paper aims to warmly invite all surgeons or physicians who perform and manage with OA procedures to participate to this international effort in order to get the best result and contribute to better understand the OA procedure.

\section{Competing interest}

All authors declare that they have no competing interest.

\section{Authors' contributions}

FC, LA and FC projected the study and wrote the paper, GM, MC, RM, NEG, EEM, WB, RI, JW, GF, AL, MS, SDS read and approved the final draft.

\section{Author details}

${ }^{1}$ General Emergency and Trauma Surgery, Papa Giovanni XXIII Hospital, Piazza OMS 1, 24127 Bergamo, Italy. ${ }^{2}$ General Surgery Department, Ospedale Maggiore, Parma, Italy. ${ }^{3}$ Denver Health Medical Center, Denver, Colorado, USA. ${ }^{4}$ Virginia Commonwealth University, Richmond, Virginia, USA. ${ }^{5}$ General Surgery, Macerata Hospital, Macerata, Italy. ${ }^{6}$ Department of Abdominal Surgery, University of Helsinki, Helsinki, Finland. ${ }^{7}$ General, Emergency and Trauma surgery, Maggiore Hospital, Bologna, Italy. ${ }^{8}$ Campinas Medical School, Campinas University, Campinas, Brazil.

Received: 3 May 2015 Accepted: 23 July 2015

Published online: 16 August 2015

\section{References}

1. McCosh II AJ. The treatment of general septic peritonitis. Ann Surg. 1897;25:687-97.

2. Burch JM, Moore EE, Moore FA, Franciose R. The abdominal compartment syndrome. Surg Clin North Am. 1996;76:833-42.

3. Carr JA. Abdominal compartment syndrome: A decade of progress. J Am Collsurg. 2013;216:135-46.

4. Perez D, Wildi S, Demartines N, Bramkamp M, Koehler C, Clavien PA. Prospective evaluation of vacuum-assisted closure in abdominal compartment syndrome and severe abdominal sepsis. J Am Coll Surg. 2007;2005(4):586-92. 
5. Balogh ZJ, Lumsdaine W, Moore E, Moore FA. Postinjury abdominal compartment syndrome: from recognition to prevention. The Lancet. 2014;384(9952):1466-75.

6. Malbrain ML, Cheatham ML, Kirkpatrick A, Sugrue M, Parr M, De Waele J, et al. Results from the international consensus of experts on intra-abdominal hypertension and abdominal compartment syndrome. I. Definitions. Intensive Care Med. 2006;32:1722-32.

7. Kirkpatrick AW, Roberts DJ, De Waele J, Jaeschke R, Malbrain MLNG, De Keulenaer B, et al. Intra-abdominal hypertension and the abdominal compartment syndrome: updated consensus definitions and clinical practice guidelines from the World Society of the Abdominal Compartment Syndrome. Intensive Care Med. 2013;39:1190-206.

8. Sugrue M, Jones F, Janjua KJ, Deane SA, Bristow P, Hillman K. Temporary abdominal closure: a prospective evaluation of its effects on renal and respiratory physiology. J Trauma. 1998:45:914-21.

9. Bosscha K, Hulstaert PF, Hennipman A, Visser MR, Gooszen HG, van Vroonhoven TJMV, et al. Fulminant acute pancreatitis and infected necrosis: results of open management of the abdomen and "planned" reoperations. J Am Coll Surg. 1998; 187:255-62

10. Cheatham ML, Safcsak K, Brzezinski SJ, Lube MW. Nitrogen balance, protein loss, and the open abdomen. Crit Care Med. 2007;35(1):127-31.

11. Collier B, Guillamondegui O, Cotton B, Donahue R, Conrad A, Groh K, et al. Feeding the open abdomen. J Parenter Enteral Nutr. 2007;31(5):410-5.

12. Dissanaike S, Pham T, Shalhub S, Warner K, Hennessy L, Moore EE, et al. Effect of immediate enteral feeding on trauma patients with an open abdomen: protection from nosocomial infections. J Am Coll Surg. 2008;207(5):690-7.

13. Cothren CC, Moore EE, Ciesla DJ, Johnson JL, Moore JB, Haenel JB, et al. Postinjury abdominal compartment syndrome does not preclude early enteral feeding after definitive closure. Am J Surg. 2004;188(6):653-8.

14. Wittmann DH, Aprahamian C, Bergstein JM, Edmiston CE, Frantzides CT, Quebbeman EJ, et al. A burr-like device to facilitate temporary abdominal closure in planned multiple laparotomies. Eur J Surg. 1993;159(2):75-9.

15. Brock WB, Barker DE, Burns RP. Temporary closure of open abdominal wounds: the vacuum pack. Am Surg. 1995;61(1):30-5.

16. Barker DE, Green JM, Maxwell RA, Smith PW, Mejia VA, Dart BW, et al. Experience with vacuum-pack temporary abdominal wound closure in 258 trauma and general and vascular surgical patients. J Am Coll Surg 2007;204(5):784-92.

17. Cheatham ML, Demetrides D, Fabian TC, Kaplan MJ, Miles WS, Schreiber MA, et al. Prospective study examining clinical outcomes associated with negative pressure wound therapy system and Barker's vacuum packing technique. World J Surg. 2013;37:2018-30

18. Miller RS, Morris Jr JA, Diaz Jr JJ, Herring MB, May AK. Complications after 344 damage-control open celiotomies. J Trauma. 2005;59(6):1365-71.

19. Boele van Hensbroek P, Wind J, Dijkgraaf MG, Busch OR, Goslings JC. Temporary closure of the open abdomen: a systematic review on delayed primary fascial closure in patients with an open abdomen. World J Surg. 2009;33(2):199-207.

20. Roberts DJ, Zygun DA, Grendar J, Ball CG, Robertson HL, Ouellet JF, et al. Negative-pressure wound therapy for critically ill adults with open abdominal wounds: a systematic review. J Trauma Acute Care Surg. 2012;73(3):629-39.

21. Rosen MJ, Krpata DM, Ermlich B, Blatnik JA. A 5-year clinical experience with single-staged repairs of infected and contaminated abdominal wall defects utilizing biologic mesh. Annals of surgery. 2013;257(6):991-6.

22. Zarzaur BL, DiCocco JM, Shahan CP, Emmett K, Magnotti $\sqcup$, Croce MA, et al. Quality of life after abdominal wall reconstruction following open abdomen. J Trauma. 2011;70:285-91.

23. Coccolini F, Agresta F, Bassi A, Catena F, Crovella F, Ferrara R, et al. Italian Biological Prosthesis Work-Group (IBPWG): proposal for a decisional model in using biological prosthesis. World J Emerg Surg. 2012;7(1):34.

\section{Submit your next manuscript to BioMed Central and take full advantage of:}

- Convenient online submission

- Thorough peer review

- No space constraints or color figure charges

- Immediate publication on acceptance

- Inclusion in PubMed, CAS, Scopus and Google Scholar

- Research which is freely available for redistribution

Submit your manuscript at www.biomedcentral.com/submit 